\title{
"Price to Pay for Being Alive": Coping with the Post-Operative Demands in Heart Transplantation
}

\author{
Evridiki Kaba ${ }^{1}$, Martha Kelesi ${ }^{2}$, Georgia Fasoi ${ }^{2}$, Fotoula Babatsikou ${ }^{2}$, George Katsimigas ${ }^{3} \&$ Areti Stavropoulou $^{4}$ \\ ${ }^{1}$ Assistant Professor, Department of Nursing, Technological Educational Institute of Athens, Greece \\ ${ }^{2}$ Associate Professor, Department of Nursing, Technological Educational Institute of Athens, Greece \\ ${ }^{3}$ Nursing Teacher at Secondary Education, 2nd Technical and Vocational Educational School (EPAL) Salamina, \\ Piraeus, Athens, Greece \\ ${ }^{4}$ Assistant Professor, Department of Nursing, Technological Educational Institute of Crete, Greece \\ Correspondence: Evridiki Kaba, Assistant Professor, Department of Nursing, Technological Educational Institute \\ of Athens, Greece. Tel: 30-210-620-0755. E-mail: evridikikaba@gmail.com
}

Received: September 13, 2016 Accepted: December 29, 2016 Online Published: January 31, 2017

doi:10.5539/gjhs.v9n3p227

URL: http://dx.doi.org/10.5539/gjhs.v9n3p227

\begin{abstract}
Introduction: Understanding the problems experienced and coping strategies used after the heart transplantation, health care providers may help heart transplant recipients' adaptation to the postoperative period and consequently improve their quality of life. However, there is little qualitative evidence on how heart transplant recipients develop coping strategies and adapt to postoperative life.
\end{abstract}

Aim: The aims of the study were a) to identify the physical and psychosocial problems experienced by heart transplant recipients and $b$ ) to identify coping strategies used by heart transplant recipients.

Methods: A grounded theory research approach was used in data collection and analysis for studying heart transplant recipients' experience. The participants in this study were 42 heart transplant recipients. The data were gathered by taped, unstructured, in-depth interviews. Constant comparison analysis was used to interpret the data.

Findings: Four categories developed from the data analysis, namely: "traumatic experience" "that's a small price to pay for being alive" "somebody else's heart inside me" and "coping". The central or core category, "That's a small price for being alive Vs Too big a price to pay for being alive" emerged and was the main theme around which other categories were integrated. Further interpretation of findings led to the development of a theory entitled "Price to pay for being alive: Coping with the post-operative demands in Heart Transplantation".

Conclusion: The theory developed within the frame of this study offers an extension of Moos' Crisis Theory, and applies his basic concepts of major life crises and transitions with adaptations, to heart transplant patients. One such adaptation is the assertion that the factors that influence how adaptively an individual copes with a heart transplant crisis are different from any other health crisis.

Keywords: coping strategies, grounded theory, heart transplantation, nursing

\section{Introduction}

Patients with advanced heart failure experience low quality of life levels. These patients experience feelings of imminent death, emotional and physical stress and the uncertainty arising from the disease. Heart transplantation has become a widely used treatment for these patients, positively influencing survival rates and gradually leading to the improvement of the patients' quality of life and well-being. In addition, heart-lung transplantation has been considered as a therapy of choice for a growing range of life-threatening illnesses. Many studies have focused on examining the quality of life of patients who have undergone heart-lung transplantation. According to these studies, recipients although demonstrate dramatic improvements in functional outcome, continue to experience psychological distress several years after surgery (Reyes, Evangelista, Doering, Dracup, Cesario, \& Kobashigawa, 2004; Grady, Naftel, Kobashigawa, Chait, Young, Pelegrin, \& McLeod, 2007; Dew, Kormos, DiMartini, Switzer, Schulberg, Roth, \& Griffith, 2001).

Heart transplantation is a tedious long-term process beginning with the preoperative procedures and continues long after the operation. This process has a significant impact to the recipients' life since patients are required to live and 
adapt to a transition period, from a terminal state of heart failure to an active lifestyle. This transition period is associated with severe changes at a physical and psychological level and therefore ongoing assessment and intervention by experienced in transplantation health professionals is necessary (Grady et al., 2007; Dressler, 1993; Karam et al., 2003). Patients who have undergone heart transplantation reported that although they experienced dramatic improvements in physical performance up to five years postoperatively their emotional well-being had considerably declined (Bunzel \& Laederach-Hofmann, 1999; Evangelista, Doering, Dracup, Vassilakis, \& Kobashigawa, 2003). It is important therefore to study the effect of the heart transplantation not only on the recipients' physical status, but also to their emotional status. The process of transplantation appears to have a considerable emotional impact as the recipients have to cope with a dual challenge: the loss of their own heart and the acceptance of a donor heart (Rogers, 1989; Godfrey, Maylin, \& Ross-White, 2012). Kaba, Thompson and Burnard, (2000) have suggested that the need to cope with the physical loss of a heart and acceptance of a donor heart may cause agony and produce feelings of psychological distress.

Recipients' experiences on coping with stress and painful feelings have been explored by several researchers. Recipients' feelings of guilt about the donor's death revealed in the study of Rauch and Kneen (1989) who demonstrate emotional turmoil and perceived threats to the integrity of the self interfere with psychological integration of the new heart. They further stressed that recipients' emotional frustration and psychological rejection of the heart is merely associated with physiological rejection.

To date, research on how recipients perceive their transplant experiences and the impacts on their lives is quite limited. Only few studies have examined in depth psychosocial adjustment and quality of life in heart transplant recipients (Mai, McKenzie, \& Kostuk, 1990; Evangelista et al., 2005) However, quality of life (QOL) and patients' well-being are closely associated to increased morbidity and mortality and thus efforts to better understand the QOL and psychological well-being of heart transplant recipients are needed (Evangelista et al., 2003; Myaskovsky et al., 2006). In depth exploration of psychological and emotional factors that may impact to recipients' life is important to the overall improvement of the heart transplant patient's quality of life (Duitsman \& Cychosz, 1993; Rybarczyk et al., 2007). Evangelista et al., (2003) state that exploring qualitative aspects of post-transplant patients is necessary as there is little research evidence in this area. Specifically, the authors reported that few data exist to allow evaluation of their qualitative findings on post-transplant women in relation to the experiences of recipients of other organ transplants.

Qualitative research methods are considered appropriate to gain in depth understanding in a field where little is known. Since, research on the psychological problems of heart transplant recipients post-operatively is limited, significant gaps in the knowledge of these problems remain. Qualitative approaches thus, are necessary in order to gain new knowledge regarding the recipient's psychological adjustment and adaptation to the postoperative life.

\section{The Study}

\subsection{Aims}

The aims of the study were:

1) To identify the physical and psychosocial problems experienced by heart transplant recipients.

2) To identify coping strategies used by heart transplant recipients

\subsection{Sample}

The participants in this study were 42 (35 male and 7 female) heart transplant recipients from one centre in Scotland, aged between 32 and 61 years, all of whom spoke English and had given consent to participate in the study. They received their transplant between 2 and 24 months before being interviewed. The participants formed purposive samples who were interviewed as they became available. Support for the study was provided by the consultant and coordinator of the heart transplant clinic. Ethical approval was sought and granted from the Local Research Ethics Committee, as previously described in detail (Kaba, Thompson, Burnard, Edwards, \& Theodosopoulou, 2005).

\subsection{Method}

A qualitative research approach, grounded theory (Glaser \& Strauss, 1967; Strauss \& Corbin, 1990) was used in subject selection, data collection, and analysis for studying heart transplant recipients' experience. Strauss (1987) referred to grounded theory methodology as a style of doing qualitative research that includes theoretical sampling, constant comparative method, and use of a coding paradigm. The purpose of using the grounded theory method was to discover categories and properties of a phenomenon which would emerge from the recipients' reports and to generate a theory that explains the phenomenon. 
Theoretical sampling was used in collecting, coding and analyzing data in a simultaneous manner. Emergent categories dictated the direction and nature of further data collection by allowing the categories that emerged from the early interviews to determine the topics covered in later ones. Theoretical sampling attempts to discover categories and their elements in order to detect and explain interrelationships between them (Glaser \& Strauss, 1967; Charmaz, 2014). The researcher proceeded to sample until the data obtained in this study were rich, and meaningful. Further data collection helped to conceptualize the boundaries and properties of each category and illuminate gaps in the emerging theory, thus highlighting where to sample next and for what theoretical purpose. Sampling continued until participants' responses reflected the participants' experiences, whereby categories and their properties were considered sufficiently dense and data collection no longer generated newleads. Thus, theoretical saturation of categories was achieved (Glaser \& Strauss, 1967). The ideas that the interviews produced in the early stage of the study served to shape the line of inquiry and in this way data collection was directed by the theoretical notions which emerged, as previously described in detail (Kaba et al., 2005).

\subsection{Data Collection}

42 heart transplant recipients provided the sample for the present study in one of their regular visits to the outpatient clinic. Unstructured, in-depth interviews were used for the data collection allowing the researcher to "enter another person's world; to understand that person's perspective" (Wilson, 1987). Interviews were tape-recorded and lasted between 30 and 45 minutes. Patients were asked to talk about problems, feelings, thoughts, attitudes, and ways of coping. Interview questions moved from general to the particular. The purpose was to elicit fundamental information in keeping with grounded theory methodology, such as dimensions, phases, properties, strategies, consequences, and contexts of behavior, as previously described in detail (Kaba et al., 2005). As conceptual categories of responses emerged from the interviews, additional questions were asked to help clarify the relationships among the categories.

For patients who needed prompts to stimulate their recollections, general questions concerning their thoughts during the post-transplant period were posed. After the opening questions, additional questions were asked only to clarify points made by the patients, to ask the patients to expand on information provided, or to ask them to comment on other patients' reported experiences. Demographic information was not sought during the interviews as all demographic data, according to Strauss (1987), need to earn their way into the grounded theory by being identified as relevant by the patients.

In the interviews for this study, although there was an agenda to help the recipients to talk, they sometimes introduced other topics they felt were relevant. A further appeal of this method is its flexibility. Rather than each recipient being asked precisely the same questions, it allowed the interviewer to pursue topics that came up that had some conceptual promise, or, indeed to introduce such ideas from earlier interviews to further develop a category. As previously described in detail (Kaba et al., 2005), the data constituted a body of information that was being constantly updated, elaborated, and refined.

The researcher kept memos of each interview. The memos contained the interviewer's perception about the participants' experiences, and the interviewer's reactions; they were also used to systematically question some of the pre-existing ideas in relation to what had been said in the interview. In these memos, comparisons were made between data, cases and codes in order to find similarities and differences, and raised questions to be answered in continuing interviews. Sometimes it was difficult to know if recipients were telling the story of their experience as they saw it, or as they would have the interviewer believe they saw it. Thus, certain steps were taken for obtaining worthwhile data. In the case of the participants, two things seemed to be important in this respect: first, that they were volunteers in the study, and second, the interviewer was not one of the members of the health care team involved in their treatment, so they could trust the interviewer.

As described by Lincoln, \& Guba, (1985) prolonged engagement is a step, that qualitative researchers take in order to improve the credibility and establish the trustworthiness of the data. Prolonged engagement is the investment of sufficient time in the data collection activities in order to learn the culture of the group under study, to test for misinformation and distortions, and to build trust with informants. For this purpose the interviewer was involved in the area of investigation long before the data collection commencement; by visiting the clinic, being introduced to the patients and talking to them, and talking to doctors and nurses to explore more information about the patients and their conditions.

Most participants had been introduced to the interviewer long before the interview and this added familiarity to the interview atmosphere as participants felt comfortable and seemed to trust the interviewer. 


\subsection{Data Analysis}

The tape recordings were transcribed and then coded line by line to identify key categories and concepts. Constant comparison analysis was used to interpret the data, as previously described in detail (Kaba et al., 2005). Using this method, emerging categories were compared with other categories in order to generate ideas about what the major concern of the individual was. These were compared with established concepts in the literature.

At that stage the main themes in the data were noted and theoretical notes were made and transferred onto index cards. According to Schatzman and Strauss (1973), if the researcher wants to go further than the "facts" he or she should write a "theoretical note". The notes represent self-conscious, controlled attempts to derive meaning from any observation. In this way the researcher is able to make interpretations of an observation that has some conceptual future.

The analysis procedure of data was based on the techniques described by Strauss and Corbin (1990) for three major types of coding: (a) open coding; (b) axial coding; and (c) selective coding. According to Strauss and Corbin (1990), coding represents the operations by which data are broken down, conceptualized, and put back together in new ways. The constant comparative method of joint coding and analysis was used [17]. There is ongoing data collection, coding, and analysis in this type of research. Glaser and Strauss (1967) identified four stages in the constant comparison method: "(1) comparing incidents applicable to each category; (2) integrating categories and their properties; (3) determining the theory; and (4) writing the theory" (p. 105). Although the stages were progressive, each stage was operational until analysis was terminated. Stern (1994) states that grounded theory methodology differs from other qualitative methodologies, as each piece of data is compared with every other piece (the constant comparative method) rather than describing only the unit under study.

As Hutchinson (1986) states, the researcher continually formulates hypotheses and rejects them if they do not seem accurate. A grounded theorist looks for contradictory data by searching out and investigating unusual circumstances or occurrences. If such data do not fit with what has already been found, they are not discarded but contribute to the richness of the theory in process. Data are compared and contrasted again and again, thus providing a check on their validity. Distortions generated by the participants will gradually be revealed. In order to evaluate the quality of the data and findings, investigator triangulation was carried out in this study. Investigator triangulation, according to Lincoln and Guba (1985), is the use of multiple individuals to collect, analyze and interpret a single set of data. Interview transcripts have been given to colleagues and researchers from other disciplines analysis, in order to improve the credibility of the research. These individuals independently categorized a sample of data trying to explore areas of disagreement and help further reduce bias; hopefully the collaboration resulted in a high rate of agreement.

Through the coding, four main categories with several subcategories were produced from the data. At this point, links between categories and potential categories also became apparent, by asking questions and making comparisons. During this process of analysis, an original set of about 20 conceptual themes were combined and integrated by means of comparing items of data, making analytic searches, and writing the interpretations of the data until the final categories were formulated. At this stage, saturation of the categories was achieved when there was no new conceptual information available to indicate new codes or the expansion of existing ones.

\section{Results}

Four categories developed from the data analysis, namely: "traumatic experience", "that's a small price to pay for being alive", "somebody else's heart inside me" and "coping". The central or core category, "That's a small price for being alive Vs Too big a price to pay for being alive" emerged in the analysis and was the main theme around which other categories were integrated. As it is not possible to present all four categories here, only the relationship on the categories and the development of the theory will be presented

Relationships of the categories: The categories were defined, developed, and integrated, and gradually were related to the core category by means of paradigm-conditions, context, strategies, and consequences. The core category "That's a small price for being alive Vs Too Big a price" represented the central phenomenon derived from the data; that was patients' satisfaction and dissatisfaction with the heart transplant experience. The category "That's a small price to pay for being alive Vs Too big a price to pay for being alive" concerned patients' perceptions of the heart transplant experience as a whole. Different interpretations were found in the data; Patients who were satisfied with the experience; patients who were satisfied with some reservations; and patients who were dissatisfied. There were patients who admitted that they were unreservedly satisfied or others who had some reservations, but because of the improved quality of life or of the importance of being alive, they accepted the problems as "that's a small price to pay for being alive". On the other hand there were patients who were 
dissatisfied and even regretted having undergone the heart transplantation admitting "that's too big a price to pay for being alive". The categories "Traumatic experience" and "Somebody else's heart inside me" were found to reflect the most common problems experienced and the changes which occurred during recipients' adjustment to postoperative life. The category "Traumatic experience" started out as a convenient 'handle' to the data concerned with problems such as postoperative medical problems, side effects of the medication, disturbance of body-image, financial and employment difficulties, marital and family problems, problems caused by hospitalization, and psychological problems that accompany the heart transplant experience. This category is also related to patients' problems caused by not being sufficiently prepared for the heart transplantation and to their concerns about changes occurring in their lives after the heart transplantation, including changes in life and life-style, changes in feelings, attitude, and personality. The category "Somebody else's heart inside me" was related to the patients' concerns about the donor's heart and how getting somebody else's heart might affect their own personality; guilty feelings for the donor's death and feelings of gratitude towards the donor's family; and concerns about their own heart. The category "Coping" concerned the different coping strategies patients in this study employed in order to deal with the problems that accompany the post-operative period of heart transplantation. An attempt was made to elicit information from patients about how the heart transplant was appraised, the type of coping strategies that they used, and whether these strategies proved effective in alleviating the problem and/or the patient's emotional distress. The core category "That's a small price for being alive Vs Too Big a price" was found to represent patients' satisfaction and dissatisfaction with the heart transplant experience; that is the outcome of the coping process with the problems experienced post-operatively.

\section{Differences in the Outcome}

Analyzing the data, it was found that there were different descriptions used by recipients in reporting the heart transplant experience and differences among recipients in the amount and type of stress that was experienced from heart transplant crisis. Recipients were classified as 'dissatisfied patients' and 'satisfied patients'. In the area of satisfaction, there were some recipients reporting total satisfaction without reservation and some others reporting satisfaction with some reservations. Heart Transplantation, even though is seen as the therapeutic procedure that prolongs life and improves health for the patients with end-stage heart diseases, is not always accompanied by satisfaction. In some cases the transplant was followed by great disappointment expressed with regrets of having the operation. These recipients saw the transplant as a trade-off, curing the heart problem but creating new problems to cope with. The "Price to pay" reflected the benefit and the costs of heart transplantation as described by patients. For some it was a "Small price to pay for being alive" while for others it was "Too big a price to pay for being alive".

\section{Factors contributing to the outcome}

Although recipients' perception of the demands and ways of coping used were found to influence the outcome, there were some other factors, such as personal, social and illness-related found to affect coping and outcome by influencing patients' perception of their situation.

\section{The role of the perception of the demands in influencing the outcome}

The perception, the meaning that was attached to the demands by heart transplant recipients in this study, was found to influence coping and adjustment in postoperative life. Whether patients perceived the heart transplantation as a "second chance" and "the gift of life" or as an "exchange of one problem with another", seemed to play an important role in determining the coping strategies they employed and whether they were satisfied or dissatisfied with their postoperative life

It is not the nature of an illness that is of uppermost importance, but rather the individual's cognitive appraisal of it (Lazarus, Averill, \& Opton, 1974; Buunk, Gibbons, \& Buunk, 2013; Tiemensma, Gaab, Voorhaar, Asijee, \& Kaptein, 2016). Miller (1986) stated that, if an illness is viewed as significant, heightened anxiety and depression are more likely to manifest themselves in an attempt to cope; if the illness is appraised as insignificant, the client will feel less personally threatened and will have greater energy for dealing with the problems presented by the illness.

Findings from this study about the role of perception in influencing the outcome found support in the literature. According to Lazarus and his colleagues (Lazarus, 1966; Lazarus \& Folkman, 1984) the outcome of a stressful transaction is mediated by appraisal and coping. Lazarus et al., (Lazarus, Averill, \& Opton, 1974; Lazarus, 1966; Lazarus et al., 1974; Lazarus \& Launier, 1978) ascribe great importance to appraisal and consider it the critical determinant of the coping process.

Regarding the issue of coping, it is important to clarify the perspective one adopts, since the goals and the 
achievement criteria of coping may be quite different, even conflicting, depending upon the point of view adopted. (Heim \& Willi 1986; Salomon et al., 2013; Davis \& Brekke, 2014; Grady et al., 2013; Grady, Andrei, Li, Rybarczyk, White-Williams, Gordon, \& McGee, 2016)

\section{The role of coping in influencing the outcome}

The outcome, namely the way recipients appraised their heart transplant experience post-operatively, found to be depended very much on how these patients coped with the various demands that accompanied the post-transplantation period. What was found to be of great importance in this study was that the selection of available coping strategies very much depended on how patients appraised the problems and on other factors that were present at the time of the selection of a particular coping strategy.

Any attempt to name ways of coping as negative or positive was avoided in this study because it was quite clear that the same ways of coping chosen by different patients had different effects. For example, talking to other heart transplant fellows was for some patients very helpful while for others, it resulted in considerable distress. While many patients seemed to talk considerably about the donor and the donor's heart, others found this to be anxiety-producing and avoided any conversation about this subject. So what was found to be helpful for some patients and was distressing for others. This is consistent with Lazarus' (1966) opinion that coping efforts that are successful for one person might have no effect, or be detrimental for others.

An example of why judgments about the effectiveness of coping strategies are likely to be inaccurate, is the use of denial as a coping strategy which can be both adaptive and maladaptive, depending on certain situations and/or at certain stages of an encounter. From the data collected, it was found that patients denied feelings toward the transplantation, the new heart and the donor. This finding is supported in the literature (Mai, 1986). This "graft and donor denial" may not be maladaptive but rather may be an aid in emotional adjustment. Patients need time to grief and think and organize how they can cope with the rigors of the heart transplant protocol. Denial may give the needed time for grief and make the emotional adjustment easier (Mai, 1986).

According to Kessler, Price, and Wortman (1985) although it is widely assumed that an appropriate choice of coping strategies can ameliorate the impact of stressful experiences, there is surprisingly little sound, empirical research bearing on this assumption.

\section{Factors influencing the coping process}

It was found in this study that heart transplant recipients' cognitive appraisal, definition of the demands involved, and the selection and effectiveness of relevant coping strategies were influenced by other factors. From the data analysis, and supported by research findings, values in life and value on life, patients' expectations and previous coping experience were found to be personal factors influencing recipients coping with the demands in the postoperative period. Present state of the illness, previous illness experience and adequacy of preparation, were seen as illness-related factors influencing the coping process. The existence or lack of social support also emerged as a factor that influenced the coping process. All these factors played an important role in influencing the coping process and the outcome of the heart transplant crisis (as shown in Figure 1.).

These factors were classified as personal, illness-related, and social factors. These findings are consistent with findings in the literature that the coping ability of a patient is influenced by several factors, including: personality, specific significance of the illness phase, previous illness experiences, available external support (Heim \& Willi, 1986; Kessler et al, 1985; Grady et al, 2013; Grady et al, 2016).

\section{Development of Theory}

\section{The theory "Price to pay for being alive: Coping with the post-operative demands in Heart Transplantation"}

The study has suggested that the experience of heart transplantation can be explained by the theory of "Price to pay for being alive: Coping with the post-operative demands in Heart Transplantation".

The goal of the theory "Price to pay for being alive: Coping with the post-operative demands in Heart Transplantation" is the assessment and subsequent prediction by health care providers of the patient's ability to accommodate and to adjust to the changes and the demands that result from the crisis. Although it is difficult to predict with certainty an individual's ability to handle this kind of stress, the theory is based on the assumption that patients' perceptions of the demands involved in heart transplantation play an important role as to whether patients experience an adaptive or maladaptive outcome. The theory explains how factors like personal, illness-related and social influence the patient's perception. The theory also explains how these factors together with the patient's perception influence the coping strategies that patients employ in order to deal with these demands. The theory 
also offers a description of the concepts involved in coping and an explanation of the relationship among the concepts.

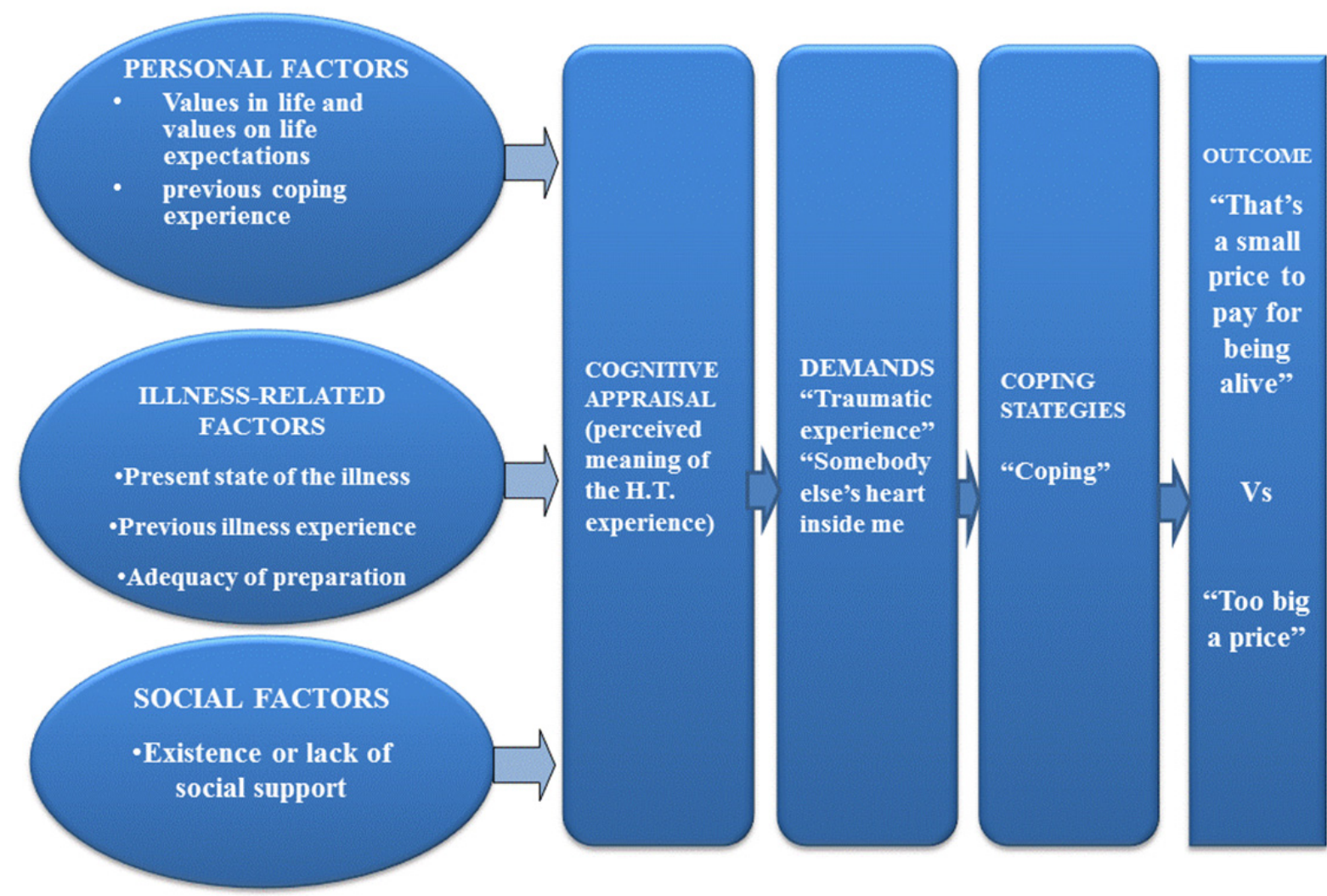

Figure 1. A conceptual framework for understanding the Heart Transplant Crisis, explaining the theory of "Price to pay for being alive: Coping with the post-operative demands in Heart Transplantation"

The conceptual framework (as explained in Figure 1) was developed to explain the theory and indicates a sequential relationship of the categories developed. The emerging framework from this study describes recipients' perceptions of the heart transplant experience post-operatively; that is the outcome of the heart transplant crisis and characterized by satisfaction or dissatisfaction. The outcome of the heart transplant crisis is described through the formation of the core variable "That's a small price to pay for being alive Vs Too big a price". The conceptual framework of the theory "Price to pay for being alive: Coping with the post-operative demands in Heart Transplantation" explains how the outcome is influenced by the coping process; namely the perceived meaning that is attached to the postoperative demands and the coping strategies employed. The coping process refers to all those cognitive and behavioral efforts that patients do in order to adjust in the post-transplantation period. The framework emphasizes that individuals' cognitive appraisal, definition of demands, and selection of coping strategies are influenced by the person, by aspects of the heart transplantation, and by the social environment.

The theory "Price to pay for being alive: Coping with the post-operative demands in Heart Transplantation" offers an extension of Moos' Crisis Theory (1977), and applies his basic concepts of major life crises and transitions with adaptations, to heart transplant patients. One such adaptation is the assertion that the factors that influence how adaptively an individual copes with a heart transplant crisis are different from any other health crisis. Because of major complications from the side effects of the use of chronic immunosuppression and the sensitive issues concerned the acceptance of the donor's heart, the heart transplantation crisis involves unique demands compared with other health crises. Moos' Crisis Theory (1977) was unable to account for the data of this study as the demands involved in heart transplantation, the coping strategies employed and all the factors that influenced the coping process, were found to be different from any other health crisis. The demands involved in the post heart transplant period are different from any other health crisis and are tasks that entail the management of stresses of chronic medication and of changes in physical functioning or appearance; role transition in the family; unemployment and financial problems; often clinic visit and various aspects of the hospital environment; concerns 
about the donor and the donor's heart and readjusting goals and expectations in light of changes brought by the heart transplantation. The categories "Traumatic experience" and "Somebody else's heart inside me" represented all those demands involved in recipients' postoperative life. According to the conceptual framework (Figure 1.) the recipient's perception of these demands can influence the employment of particular coping strategies and consequently the outcome.

According to the theory, the "Price to pay for being alive" the patient's outcome, is part of the coping process with the Heart Transplant Crisis. The outcome, how patients see and feel about the heart transplant experience post-operatively, could not be seen exclusive of the demands required and the coping strategies employed.

Patients, having undergone heart transplantation, are expected to adapt themselves in a new reality characterized by various demands. "Demands" is the name given to describe all those problems that heart transplant patients have to face post-operatively: including physical and psychological problems, financial and family problems, thoughts about the donor and the new heart, and changes that occur in patients' life and life-style, personality, attitudes and feelings. Heart transplant patients, in order to deal with these demands, employ a set of coping strategies.

The conceptual framework of the theory "Price to pay for being alive: Coping with the post-operative demands in Heart Transplantation" emphasizes that an individual's cognitive appraisal, definition of demands, and selection of coping strategies are influenced by the person, by aspects of the heart transplantation, and by the social environment. This framework is useful for identifying foci for prevention programs. Interventions can be directed at one or more of these sets of factors. For example, programs may focus on lessening the prevalence of a stressor, helping individuals avoid conditions that lead to stress, changing the appraisal of the situation, or providing information to alert individuals to the demands they will confront and to potential coping strategies for managing them.

\section{Conclusion}

The purpose of this study was to better understand the experience of living with heart transplant, exploring problems that patients' experience, and identifying coping strategies used by them. The findings of the study have generated nursing practice theory that could guide nursing interventions with these patients. Nurses, taking into consideration that changing perception and coping effectively can alter the outcome from maladaptive to more adaptive, can intervene by helping patients to change distorted perceptions and use more effective coping strategies. More information and clarification from nurses may help the patients to redefine their difficulties.

\section{Competing Interests Statement}

The authors declare that there is no conflict of interests regarding the publication of this paper.

\section{References}

Bunzel, B., \& Laederach-Hofmann, K. (1999). Long-term effects of heart transplantation: the gap between physical performance and emotional well-being. Scandinavian journal of rehabilitation medicine, 31(4), 214-222. https://doi.org/10.1080/003655099444380

Buunk, B. P., Gibbons, F. X., \& Buunk, A. (Eds.). (2013). Health, coping, and well-being: Perspectives from social comparison theory. Psychology Press.

Charmaz, K. (2014). Constructing grounded theory. Sage.

Davis, L., \& Brekke, J. (2014). Social support and functional outcome in severe mental illness: The mediating role of proactive coping. Psychiatry research, 215(1), 39-45. https://doi.org/10.1016/j.psychres.2013.09.010

Dew, M. A., Kormos, R. L., DiMartini, A. F., Switzer, G. E., Schulberg, H. C., Roth, L. H., \& Griffith, B. P. (2001). Prevalence and risk of depression and anxiety-related disorders during the first three years after heart transplantation.Psychosomatics, 42(4), 300-313. https://doi.org/10.1176/appi.psy.42.4.300

Dressler, D. K. (1993). Transplantation in end-stage heart failure. Critical care nursing clinics of North America, 5(4), 635-648.

Duitsman, D. M., \& Cychosz, C. M. (1993). Quality of Life in Heart Transplants: Indications for Education. Health Values, 17(6), 55-61.

Evangelista, L. S., Doering, L. V., Dracup, K., Vassilakis, M. E., \& Kobashigawa, J. (2003). Hope, mood states and quality of life in female heart transplant recipients. The Journal of Heart and Lung Transplantation, 22(6), 681-686. https://doi.org/10.1016/S1053-2498(02)00652-6 
Evangelista, L. S., Dracup, K., Moser, D. K., Westlake, C., Erickson, V., Hamilton, M. A., \& Fonarow, G. C. (2005). Two-year follow-up of quality of life in patients referred for heart transplant. Heart \& Lung: The Journal of Acute and Critical Care, 34(3), 187-193. https://doi.org/10.1016/j.hrtlng.2004.10.004

Glaser, B. G., \& Strauss, A. L. (1967). The Discovery of Grounded Theory: Strategies for Qualitative Research. Aldine, New York.

Godfrey, C., Maylin, S., \& Ross-White, A. (2012). Transforming self - the experience of living with another's heart: A systematic review of qualitative evidence on adult heart transplantation. JBI Database of Systematic Reviews and Implementation Reports, 10(56), 1-10. https://doi.org/10.11124/01938924-201210561-00021

Grady, K. L., Andrei, A. C., Li, Z., Rybarczyk, B., White-Williams, C., Gordon, R., \& McGee, E. C. (2016). Gender differences in appraisal of stress and coping 5 years after heart transplantation. Heart \& Lung: The Journal of Acute and Critical Care, 45(1), 41-47. https://doi.org/10.1016/j.hrtlng.2015.09.009

Grady, K. L., Naftel, D. C., Kobashigawa, J., Chait, J., Young, J. B., Pelegrin, D., ... \& McLeod, M. (2007). Patterns and predictors of quality of life at 5 to 10 years after heart transplantation. The Journal of heart and lung transplantation,26(5), 535-543. https://doi.org/10.1016/j.healun.2007.01.042

Grady, K. L., Wang, E., White-Williams, C., Naftel, D. C., Myers, S., Kirklin, J. K., ... \& Higgins, R. (2013). Factors associated with stress and coping at 5 and 10 years after heart transplantation. The Journal of Heart and Lung Transplantation, 32(4), 437-446. https://doi.org/10.1016/j.healun.2012.12.012

Heim, E., \& Willi, J. (1986). Psychosoziale Medizin Krankheitsbewaltigung. Berlin, Springer, Vol. 2 Chapt. 7.2, pp: 364-383. In Zumbrunnen, R. (1989). Coping With Heart Transplantation: A Challenge for Liaison Psychiatry. Psychother. Psychosom., 52: 66-73. https://doi.org/10.1046/j.1365-2648.2000.t01-1-01558.x

Hutchinson, S. (1986). Grounded theory: the method, in Nursing Research- A Qualitative Perspective, (eds P. Munhall and C. Oiler), Appleton- Century- Crofts, Norwalk, CT, p.111-130

Kaba, E., Thompson, D. R., \& Burnard, P. (2000). Coping after heart transplantation: a descriptive study of heart transplant recipients' methods of coping. Journal of advanced nursing, 32(4), 930-936.

Kaba, E., Thompson, D. R., Burnard, P., Edwards, D., \& Theodosopoulou, E. (2005). Somebody else's heart inside me: a descriptive study of psychological problems after a heart transplantation. Issues in Mental Health Nursing, 26(6), 611-625. https://doi.org/10.1080/01612840590959452

Karam, V. H., Gasquet, I., Delvart, V., Hiesse, C., Dorent, R., Danet, C., ... \& Castaing, D. (2003). Quality of life in adult survivors beyond 10 years after liver, kidney, and heart transplantation. Transplantation, 76(12), 1699-1704. https://doi.org/10.1097/01.TP.0000092955.28529.1E

Kessler, R. C., Price, R. H., \& Wortman, C. B. (1985). Social Factors in Psychopathology: Stress, Social Support, and Coping Processes. Ann. Rev. Psychol. 36:531-72.

Kuhn, W. F., Myers, B., Brennan, A. F., Davis, M. H., Lippmann, S. B., Gray, L. A., \& Pool, G. E. (1988). Psycopathology in heart transplant candidates. Heart Transplantation, 7, 223

Lazarus, R. S. (1966). Psychological Stress And The Coping Process. New York: McGraw-Hill.

Lazarus, R. S., \& Folkman, S. (1984). Stress, Appraisal and Coping. New York: Springer.

Lazarus, R. S., Averill, J. R., \& Opton, E. M. (1974). The psychology of coping: Issues of research and assessment. In G.V. Coehlo, D. A. Hamburg \& E. Adams (Ed.), Coping and adaptation. New York, Basic Books, 249-315.

Lazarus, R. S., Averill, J. R., \& Opton, E. M., (1970). Toward a cognitive theory of emotions. In M. Arnold (Ed.), Feelings and Emotions (pp. 207-232). New York: Academic Press. https://doi.org/10.1016/B978-0-12-063550-4.50023-1

Lazarus, R. S., \& Launier, R. (1978) Stress-Related Transactions Between Person and Environment. In L. A. Pervin, M. Lewis (Eds.), Perspectives in International Psychology. New York: Plenum

Lincoln, Y., \& Guba, E. (1985) Naturalistic inquiry. Newbury Park, CA: Sage

Mai, F. M. (1986). Graft and donor denial in heart transplant recipients. Am J Psychiatry, 143, 1159-61. https://doi.org/10.1176/ajp.143.9.1159

Mai, F. M., McKenzie, F. N., \& Kostuk, W. J. (1990). Psychosocial adjustment and quality of life following heart transplantation. The Canadian Journal of Psychiatry/La Revue canadienne de psychiatrie. 35(3), 223-227. 
Miller, J. E. (1986) Coping With Chronic Illness: Overcoming Powerness. Philadelphia: F. A. Davis.

Moos, R. (1977), (Ed.) Coping with physical illness. New York: Plenum Press.

Myaskovsky, L., Dew, M. A., McNulty, M. L., Switzer, G. E., DiMartini, A. F., Kormos, R. L., \& McCurry, K. R. (2006). Trajectories of Change in Quality of Life in 12 - Month Survivors of Lung or Heart Transplant. American journal of transplantation, 6(8), 1939-1947. https://doi.org/10.1111/j.1600-6143.2006.01395.x

Rauch, J. B., \& Kneen, K. K. (1989) Accepting the gift of life: heart transplantatrecipients post- operative adaptive tasks. Soc Work Health Care, 14, 47-59. https://doi.org/10.1300/J010v14n01_04

Reyes, C. J., Evangelista, L. S., Doering, L., Dracup, K., Cesario, D. A., \& Kobashigawa, J. (2004). Physical and psychological attributes of fatigue in female heart transplant recipients. The Journal of heart and lung transplantation, 23(5), 614-619. https://doi.org/10.1016/S1053-2498(03)00310-3

Rogers, K. R. (1989). Nature of spousal supportive behaviors that influence heart transplant patient compliance. $J$. Heart Transplant, 6:90-95.

Rybarczyk, B., Grady, K. L., Naftel, D. C., Kirklin, J. K., White-Williams, C., Kobashigawa, J., ... \& McLeod, M. (2007). Emotional adjustment 5 years after heart transplant: A multisite study. Rehabilitation Psychology, 52(2), 206. https://doi.org/10.1037/0090-5550.52.2.206

Salomon, J. A., Vos, T., Hogan, D. R., Gagnon, M., Naghavi, M., Mokdad, A., ... \& Farje, M. R. (2013). Common values in assessing health outcomes from disease and injury: disability weights measurement study for the Global Burden of Disease Study 2010. The Lancet, 380(9859), 2129-2143. https://doi.org/10.1016/S0140-6736(12)61680-8

Schatzman, L., \& Strauss, A. L. (1973). Field Research: Strategies for a Natural Sociology. Prentice Hall: Englewood Cliffs, NJ.

Stern, P. N. (1994). Eroding grounded theory, in J.M. Morse (Ed.), Critical Issues in Qualitative Research Methods (pp. 212-23). Sage, Thousand Oaks, CA.

Strauss, A., \& Corbin, J. (1990). Basics of Qualitative Research: Grounded Theory. Procedures and Techniques, Sage, Newbury Park, CA.

Strauss, B. G. (1987). Qualitative Data Analysis for Social Scientists, Cambridge University Press, Cambridge. https://doi.org/10.1017/CBO9780511557842

Tiemensma, J., Gaab, E., Voorhaar, M., Asijee, G., \& Kaptein, A. A. (2016). Illness perceptions and coping determine quality of life in COPD patients. International Journal of Chronic Obstructive Pulmonary Disease, 11, 2001. https://doi.org/10.2147/COPD.S109227

Wilson, M. Q. (1987). How to use qualitative methods in evaluation. Beverly Hills, CA: Sage.

\section{Copyrights}

Copyright for this article is retained by the author(s), with first publication rights granted to the journal.

This is an open-access article distributed under the terms and conditions of the Creative Commons Attribution license (http://creativecommons.org/licenses/by/4.0/). 